\title{
A review on Mechanism of fluid flow and Transfer of Heat in Closed Loop Pulsating Heat Pipe
}

\author{
Venkata Suresh Javvadi1 ${ }^{1, *}$, Bhramara Panitapu $^{2}$, Rajith Gangam ${ }^{3}$, Hrishikesh Kulkarni ${ }^{3}$ \\ ${ }^{1}$ Assitant Professor, Department of Mechanical Engineering, Gokaraju Rangaraju Institute of Engineering and \\ Technology, Hyderabad, India \\ ${ }^{2}$ Professor, Department of Mechanical Engineering, JNTU College of Engineering, Hyderabad, India \\ ${ }^{3} \mathrm{M}$ Tech TE Student, Department of Mechanical Engineering, Gokaraju Rangaraju Institute of Engineering and \\ Technology, Hyderabad, India
}

\begin{abstract}
Now-a-days the researchers and people are moving towards such an innovation which meet the needs of the present without compromising the ability of future generations to meet their own needs. In such innovations Pulsating heat pipe is one of the technology which started in 1990 by Akachi. Pulsating heat pipe is a heat transfer device which has an effective heat transfer capability. The researchers had done many experimental and theoretical investigations, but they haven't got the complete knowledge about it because of its complex operational mechanism which consists of hydrodynamic and thermodynamic coupling effect. This paper gives a brief idea on the thermo-hydro dynamic characteristics of this device. The brief idea will be on internal diameter, cross-section of the tube and the amount of working fluid in system. In addition to all these the number of turns in device and thermo-physical properties of working fluid which leads to determine the thermal behavior. The motto of this paper is to make review paper on recent past years on papers which used refrigerants as working fluids and its fluid flow mechanism and finally lead upcoming researchers to have basic idea and future scope of device.
\end{abstract}

\section{Introduction}

Generally, the effective heat management device is Heat pipe. There are various heat management devices like thermosyphon, loop heat pipes etc..,. Now-a-days pulsating heat pipe is special device in scientific and engineering applications. It was started in 1990 by Akachi [1]. It is a unwicked passive heat pipe which has zigzag capillary tubes. It has huge applications in electronic industries [2]-[5], aerospace, Air conditioning [6], automobile technology [7]-[9]. Following are the advantages 1) wickless structure 2) high heat transfer capacity Shang et al [10] 3) simple and compact design which made the device to use in various places in engineering applications 4) costless which lead to good amount of experiments and made the researchers easy to have keen interest. The above advantages will give a special operational mechanism. After achieving a stable condition in PHP the pulsating motion of liquid and vapour slugs move because of surface tension and capillary properties. The main impetus for throbs is the vanishing and constriction of working liquid brought about by heat ingestion and dispersal. The operational instrument includes vanishing and buildup of slight fluid film and relies upon dynamic contact edge of working liquid and follows the development and streaming of Taylor bubble standard [11]. Even though the PHP is simple design, the thermo-hydrodynamic effects during the process leads to a complicated operational mechanism which is not yet revealed fully. The PHP are three types namely a) closed loop PHP b) PHP with check valve c) open loop PHP. These are shown in Fig1.

a

b vapor slug $\mathrm{C}$
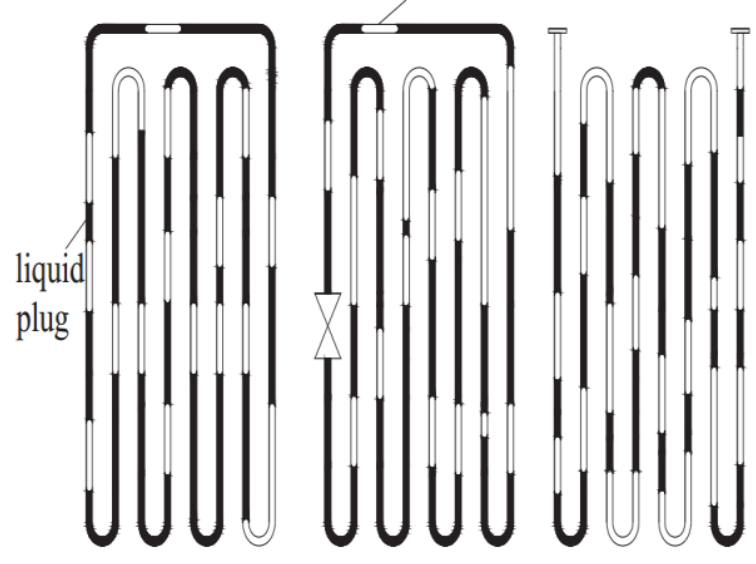

Fig.1.Classification of Pulsating heat pipe [29]

Research scholars are keenly focussing on Pulsating heat pipe because of need in the todays fast emerging world to improve the heat transfer capacity. Even

\footnotetext{
*Corresponding author: venkatasureshj@gmail.com
} 
though we have good amount of research papers till now we need the latest review paper. The researchers are mainly focussing on 3 types of investigations namely 1) Theoretical Investigations 2) Experimental Investigations 3) Numerical Investigations. In the latest trend the flow pattern and visualisation investigations are emerging to evolve in the operational mechanism.In Theoretical investigations they mainly touch the points like prototype development and qualitatively analyse the working principles (like internal thermo-hydrodynamic characteristics). In Experimental examinations the crucial point is to check the impact of every boundary on thermal resistance and heat transfer performance for that particular PHP which is developed by them. In Numerical investigations they only focus on quantity like design of PHP and reducing thermal resistance. Due to lack of understanding the experimental and numerical researches have contradictions. Although we have huge amount of theoretical and numerical work we didn't get the optimal PHP.The research scholars on PHP had been reviewed in 2008 by Zhang et al [12]. Was on modelling and few experimental data which were available till 2008. In the year 2010, khandekar et al [13]. reviewed on local hydrodynamics of oscillation motion in which he didn't cover the point like start up mechanism of PHP. In the year 2012, Xiao et al [14], reviewed experimental investigations available between 2009-2011. In the year 2016[15], Han et al. Reviewed all the theoretical and experimental data between 2012-2015.In the year 2018, Durga bastakoti et al [16]. Had reviewed on all the aspects of PHP and he also done some review refrigerants as the working fluid. So as to introduce the refreshed advancement status of PHP in utilizing Refrigerants as working liquids and a few utilization of PHP are additionally introduced and examined in this paper.

\section{HEAT TRANSFER MECHANISMS}

\subsection{HYDRODYNAMIC TRANSFER}

As the fluid is heated or heat is supplied the fluid changes into liquid slugs and vapour plugs. Because of the surface tension and gravitational force on liquid plugs and vapour slugs (gravitational force is very minute) leads to the movement in the device. There will be a formation of meniscus on both sides of the liquid/vapour.

\subsection{THERMODYNAMIC TRANSFER}

The heat removal and addition and growth of bubble formation leads to the flow in pulsating heat pipe. This is explained in general way in Groll, M., and Khandekar[17].

As the heat is transferred to the fluid from the evaporator section because of the sensible heat the fluid is heated and as the heat is continuously supplied the fluid will change its phase thus the vapour plugs and liquid slugs are formed and they oscillate in the device. This is the key fundamental force to the pulsates. The heat transfer takes in a very complex way which is needed to be analysed.

\section{PARAMETERS OF PULSATING HEAT PIPE}

There are different parameters available in the literature review. From all of the papers the parameters are majorly categorised in to the following
a) Geometrical parameters
b) Operational parameters
c) Physical parameters

a) Geometrical parameters

1) Diameter of the tube

2) Cross sectional shape of tube

3) Length of evaporator /condenser section

4) Overall length of the device

5)Number of turns

b) Operational parameters

1) Global orientation

2) Use of flow control check valve

c) Physical parameters

1) working fluid Thermo-physical properties

2) Fill ratio

\section{i) Diameter of tube}

One thing is clear that to have a movement through the surface tension we need a capillary tube which means a tube of diameter less than one centi meter. In order to have the physical behavior of pulsations in device there are different number which are made to consider for the selection of diameter of the tube. Especially the bond number critical (or Eötvös) criteria which approximately give the outline of the tube. Bond number is dimensionless which is defined as the ratio of buoyancy force to the surface tension of the working fluid.

$$
D \leq D c r=2[\sigma / g(\rho f-\rho g)]^{0.5} \text { or } \mathrm{E}_{\mathrm{o}}=\left(\mathrm{B}_{\mathrm{o}}\right)^{2}=4
$$

Where-
\begin{tabular}{|l|l|}
\hline Bo & $\begin{array}{l}\text { Bond number }=\mathrm{D} \cdot\left(\mathrm{g}\left(\rho_{\text {liq }}-\rho_{\text {vap }}\right) / \sigma\right. \\
0.5\end{array}$ \\
\hline $\mathrm{D}$ & Tube internal diameter $(\mathrm{m})$ \\
\hline$D c r$ & Critical tube diameter $(\mathrm{m})$ \\
\hline Eö & Eötvös number \\
\hline $\mathrm{g}$ & Acceleration due to gravity $\left(\mathrm{m} / \mathrm{s}^{2}\right)$ \\
\hline$\sigma$ & Surface tension $(\mathrm{N} / \mathrm{m})$ \\
\hline
\end{tabular}

\section{ii) cross sectional shape of tube}

This assumes a significant job in the pulsating heat pipe. Above Eq. 1 is applicable when a circular cross-section is used. We do have many 
researchers which have done the experiments in different cross section like M.B. Shafii et al. [18] designed a flat plate CLPHP which has rectangular cross-section in which the experiment shows an exceptionally better results than the regular circular cross-section. One more work-done by T. Chen et al. [19], numerical investigations over a flat-plate Pulsating Heat Pipes with square and rectangular cross-section. Kamlesh Mehta et al [20], The thermal resistances of the Oscillating heat pipes were explored by changing the channel shape from square to roundabout, channel sizes from $2 \times 2 \mathrm{~mm}^{2}$ to $5 \times 5$ $\mathrm{mm}^{2}$ with varying a heat input between $10-120 \mathrm{~W}$. in this they observed that using $2 \times 2 \mathrm{~mm}^{2}$ reached great thermal conductivity. The construction and movement will be very complex in different cross-sections so its better to use circular cross-section which have real and smooth flow.

\section{iii) Number of turns}

From literature review we could get that increase of number of turns will increment the thermal performance. Even though the performance is directly linked to this parameter there is no optimum number yet figured out. There are certain investigations like $\mathrm{S}$. Nawrin et al. [21] arbitrarily-chose the number of turns as 16, i.e. 8 loops Noh and Kim [22] examined the operational attributes of the pipe and relate it to the thermal method.Mameli et al. [23] chose copper PHP with 32 parallel channels to perform the experiments to look into the performance at different gravity. General excess number of turns are preferable but those are complicate to design and manufacture.

\section{iv) working fluid Thermo-physical properties}

Surface tension: From equation 1 we can observe that the surface tension is directly proportional to the critical diameter. As the surface tension increases the internal diameter increase which leads to low friction this implies low performance so from the observation we can conclude that the surface tension must below.

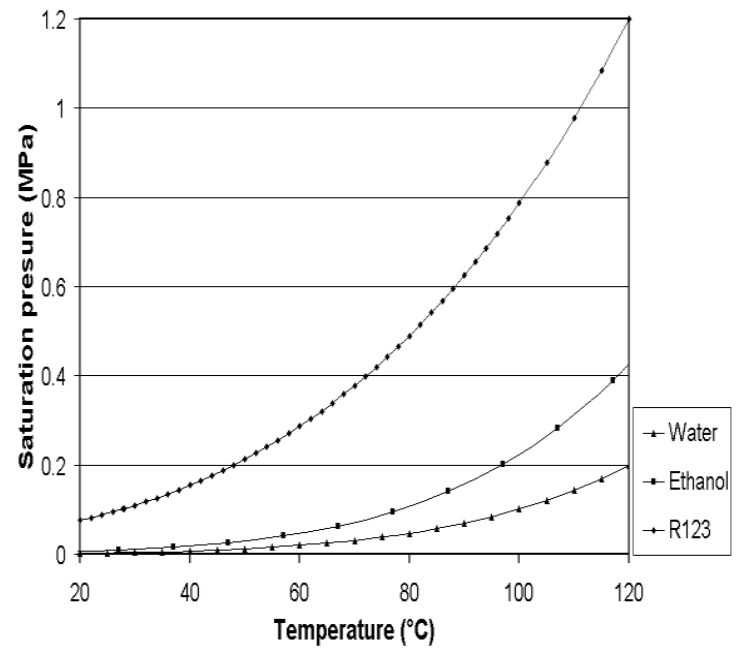

Fig. 2.variation of saturation pressure vs temperature for different working fluids [24]

Saturation pressure: The saturation pressure must be high from the Figure 2.

The ratio of the differential pressure-with respective to the temp from the fig 2 we can observe that the ratio must be higher for any working fluid. So, for any working fluid the ratio must be very high.

Viscosity: It is clear by observations that lower the viscosity will have better performance. A low viscosity will reduce the pressure losses. This will make a move towards the decrease of heat fluxto maintain pulsations. From the Fig 3 it is observed that lower the viscosity better is the performance.

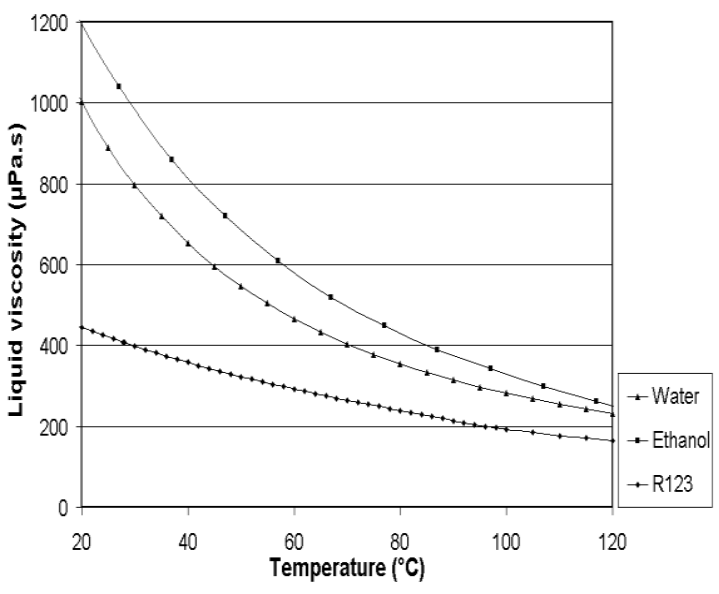

Fig. 3.Variation of Temperature with Viscosity [24]

\section{EFFECT OF REFRIGERANTS AS WORKING FLUID}

At the initial days of investigation, the working fluids like water, acetone and ethanol were frequently used. Later days as requirement in electronics and space research was increased the refrigerants are thought to be the used as working fluids. Because of similar thermophysical properties of refrigerants the following are the researches done.

Zhang et al [25], they utilized the tube with inner diameter as $1.18 \mathrm{~mm}$ with $0.41 \mathrm{~mm}$ wall thickness. The experiment was conducted between the heat input $5 \mathrm{~W}$ to $60 \mathrm{~W}$ with various charge ratios-from $60 \%$ to $90 \%$. 3 different working-fluids were used namely FC72 , deionized water and ethanol. They recorded the thermal oscillations of thin wall surface with a highspeed data-acquisition system. They observed the thermal oscillations amplitude was smaller for FC-72, because of its low surface tension than water and ethanol. In this there is an observation made by experimental studies that there is minimum heating input for initiation of pulsations when contrasted with water. 
In this the best filling-ratio is $70 \%$ for all the working fluids.

D. Torresin et al[26]. In this paper the test outcomes of an open loop type PHP with refrigerating fluids R134a and R245fa are observed. Tests are conducted for different parameters of temperature,wind stream and heat inputs. The preliminary outcomes show the various thermo-physical properties effect of the two tried fluids on the cooler presentations: R134a is more changed in accordance with low inundation temperature than R245fa and the inverse has been seen at high submersion temperatures. This is because of the way that R245fa arrives at its gooey limitat low temperatures while at high temperatures R134a arrives at its basic temperature.

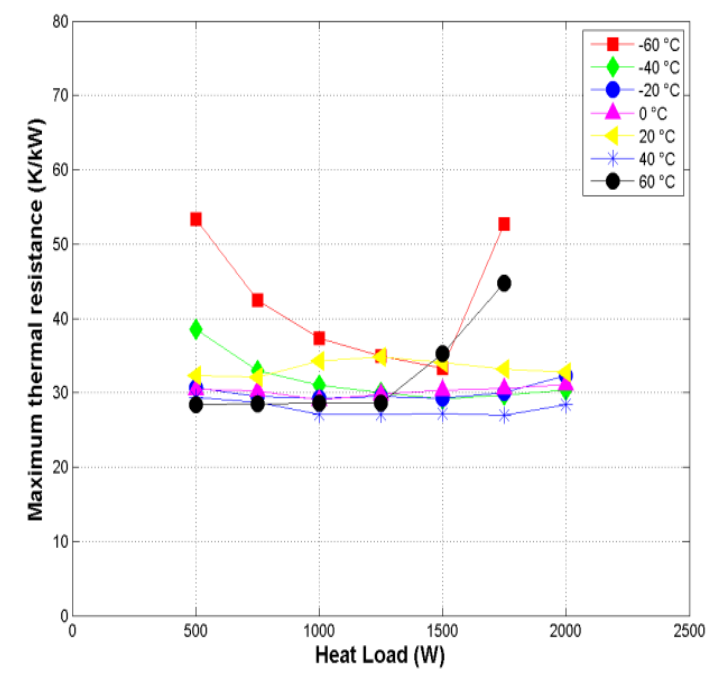

Fig. 4. R134a Heat Load vs Maximum Thermal Resistance [26]

From Fig 4 it tends to be seen, the PHP cooler is working for all the tried air temperature-conditions in the scope of heat load structure 500 to $1750 \mathrm{~W}$. The maximum thermal resistance remains practically steady for air temperatures between $-20{ }^{\circ} \mathrm{C}$ and $40{ }^{\circ} \mathrm{C}$ in the whole scope of tried warmth loads. At $-60{ }^{\circ} \mathrm{C}$ and $60{ }^{\circ} \mathrm{C}$ air temperatures, a sharp increment of the most extreme warm obstruction is watched for heat loads higher than $1.5 \mathrm{~kW}$. At this heat load the liquid immersion pressure is near the basic state. At air temperatures underneath $40{ }^{\circ} \mathrm{C}$ the thermal resistance is expanding with the lessening of the heat load; this conduct is connected to the expansion of the viscous forces.

In general R134a performs better than R245fa however the ideal working extent is unique: R134a is more adjusted to low immersion temperature than R245fa which arrives at its thick breaking point, while despite what might be expected, at high immersion temperature, R134a arrives at its basic temperature.

Giulia Spinato et al [27] Synchronized warm and visual examination was completed on a solitary turn channel CLPHP utilizing R245fa as the working liquid. The tests were done at filling proportions from 10 to
$90 \%$ and warm contributions from 2 to $60 \mathrm{~W}$ for vertical and inclined directions. A deliberate investigation of the stream designs, their changes and thermal resisance estimations recommends a solid coupling between the two-phase stream design and the framework thermal conduct. In view of this examination, meager film vanishing was seen as the predominant warm system, while heat move into the oscillating fluid slug and restricted nucleate bubbling were of optional significance.

D. Mangini et al [28] A hybrid CLPHP with an ID bigger than the capillary-threshold is tested both on ground and in microgravity conditions. The gadget, in part topped off with FC-72, comprises of an aluminum tube (internal distance across: $3 \mathrm{~mm}$ ) twisted into a planar serpentine with five bends at the evaporator. A straightforward area shuts the circle in the condenser zone, permitting liquid stream representation. Five heaters are mounted altenatively on the branches, simply over the turns and controlled freely, so as to examine the impact of non-uniform heating arrangements. On ground, where the gadget fills in as a thermosyphon, the non-uniform heating arrangements advance the liquid net- circulation in a special way, expanding the thermalperformance as for the homogeneous-heating. Illustrative flights call attention to that during the $20 \mathrm{~s}$ of microgravity, the abrupt nonappearance of the lightness power actuates a swaying slug/plug stream system, average of the PHP, permitting the gadget to work likewise without the help of gravity.

\section{Conclusion}

PHP's are highly attractive heat-transfer elements, which due to their simple design, cost effectiveness and excellent thermal-performance may find veriety applications. Since their innovation in the mid nineties, so far they have discovered market specialties in gadgets hardware cooling. The work consolidated here fundamentally expands the comprehension of the marvels and impact of working liquids that oversee the performance of PHP.The refrigerants as working fluid may have prominent role in future. Many unsolved issues are present in the operational mechanism and in many parts further investigationin field may over all the challenges.

\section{References}

1. H. Akachi, Structure of heat pipe, US Patent, 4921041 (1990)

2. M. Jalilian, H. Kargarsharifabad, A. Abbasi Godarzi, A. Ghofrani, and M. B. Shafii, Simulation and optimization of pulsating heat pipe flat-plate solar collectors using neural networks and genetic algorithm: a semi-experimental investigation, Clean Technology Environment Policy, 18, 2251-2264 (2016) 
3. Z. Said, M. H. Sajid, M. A. Alim, R. Saidur, and N. A. Rahim, Experimental investigation of the thermophysical properties of $\mathrm{Al} 2 \mathrm{O} 3$ - nano fluid and its effect on a flat plate solar collector, International Communications in Heat and Mass Transfer, 48 , 99-107 (2013)

4. P. Stule, F. Polasek, Cooling of electronic elements by miniature and medium-sized heat pipe, Proceedings of the European Thermal Science Conference (1996)

5. S. Harmand, R.Sonan, M. Fakes, and H. Hassan, Transient cooling of electronic components by flat heat pipes, Applied Thermal Engineering, 31, 1877-1885 (2011)

6. D. Torresin, F. Agostini, A. Mularczyk, B. Agostini, and M. Habert, Double condenser pulsating heat pipe cooler, Applied Thermal Engineering, 126, 1051-1057, (2017)

7. G. Burban, V. Ayel, A. Alexandre, P. Lagonotte, Y. Bertin, and C. Romestant, Experimental investigation of a pulsating heat pipe for hybrid vehicle applications, Applied Thermal Engineering, 50, 94-103 (2013)

8. M. L. Rahman, R. A. Sultan, T. Islam, N. M. Hasan, and M. Ali, An experimental investigation on the effect of fin in the performance of closed loop pulsating heat pipe (CLPHP), Procedia Engineering, 105, 137-144 (2015)

9. V. Manno, S. Filippeschi, M. Mameli, C. Romestant, V. Ayel, and Y. Bertin, ThermalHydraulic Characterization of a Flat Plate Pulsating Heat Pipe for Automotive Applications, Interfacial Phenomena and Heat Transfer, 3, 413-425 (2015)

10. F.M.Shang, D.Y.Liu,H.Xian, J.H.Liu,. Experimental investigation on enhanced heat transfer of self-exciting mode oscillating-flow heat pipes, J Eng Ther- mophys, 30(3), 461-464 (2009)

11. M.Balkrishna, K.Sameer, Taylor bubble-train flows and heat transfer in the context of Pulsating Heat Pipes, International Journal of Heat and Mass Transfer, 79, 279-290 (2014)

12. Y. Zhang, A. Faghri, Advances and Unsolved Issues in Pulsating Heat Pipes, Heat Transfer Engineering, 28, 20-44 (2008)

13. S.Khandekar, P.K.Panigrahi, F.Lefevre, J.Bonjour Local hydrodynamics of flow in a pulsating heat pipe: a review, Front Heat Pipes, 1(1), 1-20 (2010)

14. L.Xiao, Y.Cao Recent advances in pulsating heat pipes and its derivatives, J Enhanced Heat Transfer 19(3), 213-31 (2012)

15. X. Han, X. Wang, H. Zheng, X. Xu, and G. Chen, Review of the development of pulsating heat pipe for heat dissipation, Renewable and Sustainable Energy Reviews, 59, 692-709 (2016)

16. D. Bastakoti, H. Zhang, D. Li, W. Cai, F. Li, An Overview on the Developing Trend of Pulsating Heat Pipe and its Performance, Applied Thermal Engineering, 141, 305-332 (2018)
17. M.Groll, S.Khandekar, Pulsating Heat Pipes: Progress and Prospects, Proc. International Conference on Energy and the Environment, Shanghai, China, 1, 723-730 (2003)

18. M. Ebrahimi, M.B. Shafii, M.A. Bijarchi, Experimental investigation of the thermal management of flat-plate closed-loop pulsating heat pipes with interconnecting channels, Applied Thermal Engineering, 90, 838-847 (2015)

19. D. Xu, T. Chen, Y. Xuan, Thermo-hydrodynamics analysis of vapor-liquid two-phase flow in the flatplate pulsating heat pipe, International Communications in Heat and Mass Transfer, 39, 504-208 (2012)

20. M.Kamlesh, M.Nirvesh, Vivek Patel, Influence of the channel profile on the thermal resistance of closed loop flat plate oscillating heat pipe, Journal of the Brazilian Society of Mechanical Sciences and Engineering, 42, 1-12 (2020)

21. M. L. Rahman, S. Nawrin, R. A. Sultan, F. Mir, M. Ali, Effect of fin and insert on the performance characteristics of close loop pulsating heat pipe (CLPHP), Procedia Engineering, 105, 129-136 (2015)

22. H. Y. Noh, S. J. Kim, Experimental Investigation of Fluid Motion in Pulsating Heat Pipe, ASME Proceedings, Thermal Management,1 (2015)

23. M. Mameli, L. Araneo, S. Filippeschi, L. Marelli, R. Testa, and M. Marengo, Thermal response of a closed loop pulsating heat pipe under a varying gravity force, International Journal of Thermal Sciences, 80, 11-22 (2014)

24. K.Sameer, Thermo-Hydrodynamics of closed loop pulsating heat pipes, Ph.D Thesis, (2004)

25. Srinivasa Rao D, Sandhya Rani MN, Sarfaraz Nawa z Syed and Suresh Kumar Tummala, E3S Web of Conferences 8701003 (2019)

26. D. Torresin, M. Habert, V. Mounier, F. Agostini, and B. Agostini, Characterisation of a novel pulsating heat pipe cooler for power electronics at extreme ambient temperatures, 13th International Conference on Nanochannels, Microchannels, and Minichannels, ICNMM (2015), collocated with the ASME 2015 International Technical Conference and Exhibition on Packaging and Integration of Electronic and Photonic Microsystems (2015)

27. G. Spinato, N. Borhani, and J. R. Thome, Operational regimes in a closed loop pulsating heat pipe, International Journal of Thermal Sciences, 102 78-88, (2016)

28. D. Mangini, M. Mameli, D. Fioriti, S. Filippeschi, L. Araneo , M. Marengo, Hybrid Pulsating Heat Pipe for space applications with non-uniform heating patterns: Ground and microgravity experiments, Applied Thermal Engineering 126, 1029-1043, (2017)

29. S. Khandekar, Pulsating heat pipe based heat exchangers, Proc. 21st International Symposium on 
Transport Phenomena, Kaohsiung City, Taiwan, (2010) 